\title{
Educação Infantil e a Base Nacional Comum Curricular: concepções de criança, desenvolvimento e currículo ${ }^{1}$
}

\section{Preschool and the National Curricular Common Base: conceptions of child, development and curriculum}

\section{Educación Infantil y la Base Nacional Común Curricular: Concepciones de niño, desarrollo y currículo}

Ana Maria Esteves Bortolanza²

Renata Teixeira Junqueira Freire ${ }^{1}$

DOI: http://dx.doi.org/10.20435/serie-estudos.v23i49.1138

\begin{abstract}
Resumo: Este estudo resulta de uma pesquisa bibliográfica e documental sobre as concepções de criança, de desenvolvimento infantil e de currículo presentes na Base Nacional Comum Curricular da Educação Infantil (BNCC, 2017). Analisa, principalmente, os eixos curriculares denominados na BNCC como Campo de Experiências buscando compreender as bases teóricas que norteiam a organização do documento, a partir das contribuições de Vygotsky sobre desenvolvimento infantil, num processo de apropriação das qualidades humanas por meio da atividade, portanto o desenvolvimento da singularidade humana se dá a partir das interações sociais. Estudos de Kramer, Kishimoto e de outros autores constituem as referências bibliográficas desta pesquisa. Constata-se que a BNCC apresenta uma concepção de criança como sujeito histórico-cultural, no entanto o documento contém fragilidades e requer um aprofundamento das áreas de conhecimento identificadas como Campos de Experiências. Aponta-se como fundamental a necessidade de estudos e discussões sobre as concepções de criança e de desenvolvimento infantil para a organização curricular e para a formação de professores que atuam ou que pretendem atuar na Educação Infantil.
\end{abstract}

Palavras-chave: infância; Educação Infantil; Base Nacional Curricular Comum.

Abstract: This study results from a bibliographical and documentary research on the conceptions of children, children's development and curriculum present in the National Curricular Common Base for Early Childhood Education (BNCC, 2017). It analyses, mainly, the curricular axes denomi-

\footnotetext{
${ }^{1}$ Apoio CNPq.

${ }^{2}$ Universidade de Uberaba (UNIUBE), Uberaba, Minas Gerais, Brasil.
} 
nated in the BNCC as Field of Experiences seeking to understand the theoretical bases that guide the organization of the document, from the contributions of Vygotsky on child development in a process of appropriation of the human qualities through the activity, therefore the development of human singularity is based on social interactions. Studies of Kramer, Kishimoto and other authors constitute the bibliographical references of this research. BNCC presents a conception of children as a historical-cultural subject, however the document contains fragilities and requires a deepening of the areas of knowledge identified as Fields of Experiences. It is pointed out as fundamental the necessity of studies and discussions on the conceptions of children and child development for the curricular organization and for the formation of teachers who act or who intend to act in Early Childhood Education.

Keywords: childhood; Preschool; National Common Curricular Base.

Resumen: Este estudio resulta de una investigación bibliográfica y documental sobre las concepciones de niño, de desarrollo infantil y de currículo presentes en la Base Nacional Común Curricular de la Educación Infantil (BNCC, 2017). Se analiza, principalmente, los ejes curriculares denominados en la BNCC como Campo de Experiencias buscando comprender las bases teóricas que orientan la organización del documento, a partir de las contribuciones de Vygotsky sobre desarrollo infantil en un proceso de apropiación de las calidades humanas por medio de la actividad, por lo tanto el desarrollo de la singularidad humana se da a partir de las interacciones sociales. Los estudios de Kramer, Kishimoto y otros autores constituyen las referencias bibliográficas de esta investigación. Se constata que la BNCC presenta una concepción de niño como sujeto histórico-cultural, sin embargo el documento contiene fragilidades y requiere una profundización de las áreas de conocimiento identificadas como Campos de Experiencias. Se apunta como fundamental la necesidad de estudios y discusiones sobre las concepciones de niño y de desarrollo infantil para la organización curricular y para la formación de profesores que actúan o que pretenden actuar en la Educación Infantil.

Palabras clave: infancia; Educación Infantil; Base Nacional Curricular Común.

\section{INTRODUÇÃO}

A trajetória da Educação Infantil brasileira é marcada por muitos debates que vão desde o seu lugar na educação brasileira, sua função e seus objetivos, a definição de faixa etária, a formação dos profissionais que atuam ou pretendem atuar nesse segmento. Nesse cenário, pesquisas, documentos, propostas pedagógicas e aspectos legais têm permeado a discussão sobre a Educação Infantil e o currículo. No que se refere aos documentos oficiais sobre a Educação Infantil no Brasil, encontramos o Referencial Curricular Nacional da Educação Infantil, as Diretrizes Curriculares Nacionais da Educação Infantil e, recentemente, a Base Nacional Comum Curricular da Educação Infantil (BNCC).

Propomos nesse texto uma análise da BNCC da Educação Infantil com foco na concepção de criança, de desenvolvimento e de currículo. Identificamos, 
em alguns aspectos apresentados na BNCC, que o documento faz referência ao Referencial Curricular para a Educação Infantil e às Diretrizes Curriculares da Educação Infantil. Em relação à legislação brasileira, desde a promulgação da Lei de Diretrizes e Bases (1996), a Educação Infantil passou a integrar a Educação Básica. A Lei 11.274/2006 estabelece que as crianças de 6 anos sejam matriculadas no primeiro ano do Ensino Fundamental. Assim, a Educação Infantil no Brasil atende a crianças de 0 a 5 anos, sendo obrigatória para as crianças de 4 e 5 anos, de acordo com a emenda constitucional datada de 2009. Essas considerações iniciais são importantes para entendermos como a Educação Infantil, enquanto segmento da educação, situa-se na organização da Educação Brasileira. Estamos, portanto, nos referindo a um nível de escolaridade que integra a educação básica e engloba crianças de 0 a 5 anos, mas que define a obrigatoriedade escolar apenas para as crianças de 4 a 5 anos.

Encontramos aqui um primeiro aspecto que merece discussão. A BNCC da Educação Infantil apresenta em sua estrutura uma proposta para crianças de 0 a 5 anos. A não obrigatoriedade ou a não garantia do direito efetivo de as crianças de 0 a 3 anos participarem do contexto educativo na Educação Infantil já traz questionamentos sobre a relativa importância que é conferida à educação das crianças nos primeiros anos de vida. Parece-nos que, nesse sentido, a Educação Infantil ainda não constitui prioridade nas políticas públicas educacionais, embora entendamos que houve um avanço ao incluir a Educação Infantil na Educação Básica. Entretanto há ainda um caminho a ser percorrido para que de fato a Educação Infantil seja um direito legal da criança, legitimado pelo Estado e pela sociedade.

O estudo aqui apresentado foi organizado em nove tópicos que tratam da temática em questão em relação à estrutura da Educação Infantil explicitada na Base Nacional Comum Curricular; à concepção de criança, à concepção de desenvolvimento na BNCC; à proposta curricular da Educação Infantil na BNCC; e à questão da avaliação na Educação Infantil. Seguem as considerações finais em que pontuamos os resultados do estudo.

\section{A ESTRUTURA DA EDUCAÇÃO INFANTIL NA BASE NACIONAL COMUM CURRICULAR}

O texto sobre a Educação Infantil na BNCC apresenta os eixos estruturantes para esse nível de escolaridade, os campos de experiências e os objetivos de 
aprendizagem e desenvolvimento que foram pensados por Campo de Experiências. O documento organiza os objetivos para três faixas etárias: crianças de 0 a 1 ano e seis meses, crianças de 1 ano e sete meses a 3 anos e 11 meses, crianças de 4 e 5 anos e 11 meses. São considerados eixos estruturantes na Educação Infantil as interações e as brincadeiras. A definição dos eixos explicitada no texto da BNCC se articula com as Diretrizes Curriculares Nacionais da Educação Infantil. Encontramos seis direitos de aprendizagem e de desenvolvimento que devem ser assegurados às crianças brasileiras: direito de conviver, direito de brincar, direito de participar, direito de explorar, direito de expressar e direito de conhecer-se. No documento, são apresentados os Campos de Experiências que traduzem o arranjo curricular pensado para a Educação Infantil. São apresentados os seguintes campos de experiências: o eu, o outro e o nós; corpo, gestos e movimentos; traços, sons, cores e formas; oralidade e escrita; espaços, tempos, quantidades, relações e transformações. Por meio de quadros, são apresentados os objetivos de aprendizagem e de desenvolvimento para cada campo de experiências correspondente às três faixas etárias já mencionadas. O documento finaliza com as considerações sobre a transição da Educação Infantil para o Ensino Fundamental apresentando um quadro síntese das aprendizagens necessárias para essa transição. Os eixos estruturantes; direitos de aprendizagem; campos de experiências/objetivos de aprendizagem e desenvolvimento, as considerações sobre a transição para o ensino fundamental e o quadro síntese das aprendizagens necessárias para essa transição constituem a estrutura da BNCC da Educação Infantil.

\section{CONCEPÇÃO DE CRIANÇA E DE DESENVOLVIMENTO}

O modo como compreendemos a criança foi ponto de partida, porque a concepção de criança influi com a direção que damos ao trabalho educativo na Educação Infantil. Nesse sentido, se concebemos a criança de modo infantilizado, podemos minimizar as capacidades da criança: Ela não consegue ou É muito pequena ou ainda Não entende desses assuntos. Essas e outras observações podem se constituir em afirmativas que traduzem uma concepção que não considera a criança como sujeito capaz de pensar, sentir, conviver e agir no contexto em que está inserida. Práticas pedagógicas decorrentes dessa concepção nem sempre são marcadas por uma intencionalidade pedagógica e são organizadas intuitivamente pela visão do que a criança, aparentemente, gosta e consegue fazer. 
De outro lado, encontramos uma concepção de criança que a considera como um adulto em miniatura. Nesse enfoque, as práticas educativas não consideram a Educação Infantil como um nível de escolaridade com função pedagógica própria, entendendo essa etapa como fase de preparação para a etapa seguinte. Nessa visão, a criança é alguém que deve ser moldada na Educação Infantil para ter sucesso no Ensino Fundamental.

Decorrentes dessa concepção, o foco na linguagem ainda tem sido o ensino do código linguístico em substituição à leitura e escrita e o ensino de número voltado para o conhecimento lógico matemático. As frases - Entrego os meus alunos lendo e escrevendo e Eles já sabem somar e subtrair até 10 - são afirmativas que ouvimos e nos perguntamos: Quais são as possibilidades de desenvolvimento da criança nessa perspectiva? A Educação Infantil se constituiria em uma escolarização preparatória para o ensino fundamental?

A partir dessas considerações iniciais, este estudo tem como objetivo compreender a concepção de criança, de desenvolvimento infantil e de currículo defendida na BNCC.

Entendemos que, ao se definir como eixos estruturantes da Educação Infantil a brincadeira e a interação, já nos deparamos com uma concepção de criança como sujeito social que aponta a ludicidade como um caminho metodológico. A definição dos direitos de aprendizagem também revela uma concepção de criança, pois, ao eleger, por exemplo, o direito de explorar, compreendemos a criança como um sujeito capaz de pensar, de fazer descobertas. Quando analisamos cada um dos direitos apresentados na BNCC para a Educação Infantil, constatamos que o documento se refere a uma criança como sujeito inteiro e desenvolvimento integral.

Na BNCC para a Educação Infantil, identificamos a seguinte referência à concepção de criança:

Essa concepção de criança como ser que observa, questiona, levanta hipóteses, conclui, faz julgamentos e assimila valores e que constrói conhecimentos e se apropria do conhecimento sistematizado por meio da ação e nas interações com o mundo físico e social não deve resultar no confinamento dessas aprendizagens a um processo natural ou espontâneo. (BRASIL, 2017, p. 34).

A criança é vista como um sujeito capaz, sujeito que pensa, que sente, que se expressa, que convive, que aprende, que interage com o mundo físico e social. Não é, portanto, uma concepção de criança infantilizada nem de uma 
criança como adulto em miniatura, mas uma criança que apresenta capacidades e possibilidades de aprendizagem e de desenvolvimento. Ao analisarmos a concepção de criança expressa no documento, relacionamos essa concepção à perspectiva histórico-cultural de criança, especialmente com os estudos de Vygotsky, que contribuem para entendermos a criança e o seu processo de desenvolvimento.

Vygotsky defende que o desenvolvimento caminha do nível social (interpsíquico) para o nível individual (intrapsíquico), e se realiza em dois planos.

Qualquer função no desenvolvimento cultural da criança aparece duas vezes ou sobre dois planos. Primeiro aparece no plano social, e só então no plano psicológico. Inicialmente aparece entre pessoas como uma categoria interpsicológica, e então, como uma categoria intrapsicológica. (VYGOTSKY, 1998, p. 75).

Cabe ressaltar a importância da interação social para o processo de desenvolvimento da criança. Essa compreensão pode ampliar a visão de educadores que limitam a Educação Infantil a espaço necessário para a socialização da criança. Entendemos que a interação social consiste em um conceito muito mais profundo para o desenvolvimento infantil, que não pode ser limitado a lugar de socialização das crianças. De acordo com Vygotsky (1998), as funções psicológicas superiores como, a memória, o pensamento, a linguagem pode desenvolver-se a partir da interação social vista como uma relação da criança com o outro que a constitui como ser humano.

Assim, quando defendemos a interação social como necessária ao processo de apropriação de conhecimentos, precisamos esclarecer que a aprendizagem não é cópia do social e que a criança não é uma tábula rasa em que vão sendo impressos conhecimentos e experiências. A criança é um ser biológico, social, cultural, pensante, afetivo, singular que reconstrói o que se apropriou no plano social, tornando seus os conhecimentos apropriados e, simultaneamente, desenvolvendo suas funções psicológicas superiores.

Os conceitos de processo de internalização e da evolução da linguagem propostos por Vygotsky (1998) contribuem para entendermos o processo de reconstrução do social pela criança. O autor denominou internalização o processo de reconstrução interna de uma operação externa e destacou que o processo de internalização consiste numa série de transformações: 
a- Uma operação que inicialmente representa uma atividade externa é reconstruída e começa a ocorrer internamente.

b- Um processo interpessoal é transformado num processo intrapessoal. c- A transformação de um processo interpessoal num processo intrapessoal é o resultado de uma longa série de eventos ocorridos ao longo do desenvolvimento. (VYGOTSKY, 1998, p. 75).

Os processos de internalização são marcados por transformações, o que nos leva a compreendê-lo como um processo dinâmico no espaço escolar da Educação Infantil. Enfatizamos a necessidade de compreendermos a importância da concepção de interação social no processo de aprendizagem, pois as crianças não aprendem de modo mecânico e não fazem uma cópia do real. O entendimento do que vem a ser o processo de internalização nos traz a ideia de sua complexidade enquanto atividade interna que a criança realiza da cultura, do seu meio social.

É preciso analisar como a criança se expressa em suas diferentes formas de linguagem para compreendermos como se apropria de conhecimentos, ideias, valores. Se ela não tem oportunidade de expressão e só responde mecanicamente a comandos, não podemos conhecer como compreende o mundo e como dele se apropria. O processo de apropriação e de reelaboração do plano social pela criança tem como base as operações com os signos, pois "é pela mediação dos signos que a criança se incorpora progressivamente à comunidade humana, internalizando sua cultura e tornando-se um indivíduo social, ou seja, humanizado (SIRGADO, 2000, p. 36).

Ao nos referirmos à mediação de signos, refletimos o papel fundamental da linguagem nos processos de internalização e, consequentemente, na sua importância para a constituição do indivíduo.

A psique em toda a sua complexidade e mutabilidade, origina se no plano social, graças à atividade produtiva. Individualiza-se pelas interações que tem na linguagem o veículo fundamental- e, novamente, pelos meios, socializa-se. Em resumo, é essa dialética responsável pelo milagre do psiquismo humano. (PALANGANA, 1995, p. 24).

Quando pensamos na criança como sujeito histórico social, sujeito inteiro capaz de pensar sentir, expressar, conviver, aprender, nos perguntamos: como se dá seu desenvolvimento e como se dá a relação desenvolvimento e aprendizagem? Na perspectiva vigotskiana, a aprendizagem e o desenvolvimento se inter-relacionam desde o primeiro dia de vida da criança. De acordo com Vygotsky, 
para compreendermos as relações reais entre desenvolvimento e aprendizagem, temos que determinar dois níveis de desenvolvimento.

O primeiro nível pode ser chamado de nível desenvolvimento real, isto é, o nível de desenvolvimento das funções mentais da criança que se estabeleceram como resultado de certos ciclos já completados [...] E o nível de desenvolvimento potencial, determinado através da solução de problemas sob a orientação de um adulto ou em colaboração com companheiros mais capazes. (VYGOTSKY, 1998, p. 111).

Entendemos que o nível de desenvolvimento real refere-se àquilo que a criança consegue realizar sozinha, de forma autônoma, enquanto o nível de desenvolvimento potencial é o que a criança pode aprender com o auxílio de pessoas mais experientes. O desenvolvimento potencial é, nessa perspectiva:

[...] a distância entre o nível de desenvolvimento real, que se costuma determinar através da solução independente de problemas, e o nível de desenvolvimento potencial, determinado através da solução de problemas sob a orientação de um adulto ou em colaboração com companheiros mais capazes. (VYGOTSKY, 1998, p. 117).

Mais uma vez se confirma a importância da interação social para o desenvolvimento da criança. Cabe esclarecer que, nessa perspectiva, não entendemos que primeiro a criança se desenvolve e depois aprende, que desenvolvimento e aprendizagem são processos idênticos, nem concebemos uma linearidade nos processos de desenvolvimento e aprendizagem. Corroboramos com os estudos de Vygotsky para quem desenvolvimento e aprendizagem inter-relacionam-se, sendo que a aprendizagem pode suscitar processos de desenvolvimento da criança.

Um aspecto essencial do aprendizado é o fato dele criar a zona de desenvolvimento proximal; ou seja, o aprendizado desperta vários processos internos de desenvolvimento, que são capazes de operar somente quando a criança interage com pessoas em seu ambiente. (VYGOTSKY, 1998, p. 118).

Ao pensarmos na relação desenvolvimento e aprendizagem, nos perguntamos se esta concepção dialoga com os princípios da BNCC e quais áreas do conhecimento devem integrar o projeto pedagógico, e ainda como pode ser entendida a avaliação na Educação Infantil. Consideramos que essa concepção dialoga com alguns princípios apresentados na BNCC. Destacamos mais uma vez que a escolha da interação como um dos eixos estruturantes na Educação Infantil 
pode evidenciar a interação como a base para os processos de aprendizagem e desenvolvimento.

Analisamos a seguir os campos de experiências e os objetivos de desenvolvimento e aprendizagem na BNCC buscando identificar se há uma coerência entre a concepção de criança e a relação entre desenvolvimento e aprendizagem apresentada.

\section{A PROPOSTA CURRICULAR DA EDUCAÇÃO INFANTIL NA BNCC}

Historicamente, a questão do currículo vem sendo discutida e compreendida sob diferentes enfoques. O que é um currículo? Quem é responsável pela elaboração do currículo? Quais são os aspectos que devem integrar o currículo?

O currículo na Educação Infantil já foi entendido sem uma intencionalidade, na perspectiva de aprendizagem como processo natural. Há também posições que defendem a diretividade como princípio curricular e, a partir dessa compreensão, foram definidos conteúdos/objetivos a serem trabalhados em cada ano de escolaridade, em diversas áreas do conhecimento. Outra forma de ver o currículo presente na escola de Educação Infantil assenta-se na organização do trabalho planejado em função de datas comemorativas aliado à preparação da criança para o Ensino Fundamental.

A ampliação de pesquisas, estudos, debates em torno da questão do currículo tem aprofundado a reflexão sobre o tema. Kishimoto retoma a etimologia da palavra currículo, derivada do termo latino currus-carro, que significa um lugar no qual se corre. Seu uso metafórico em educação seria a busca de um caminho, de uma direção, que orientaria para atingir certas finalidades. A autora defende "currículo como explicitação de intenções que dirigem a organização da escola" (KISHIMOTO, 1994, p. 13).

Kramer, ao explicar o que significa currículo, utiliza a expressão proposta pedagógica como um caminho concreto.

Uma proposta pedagógica é um caminho, não um lugar. Uma proposta pedagógica tem uma história que precisa ser contada. Toda proposta contém uma aposta. Nasce de uma realidade que pergunta e é também busca de uma resposta". (KRAMER, 1997, p. 19).

Compreendemos currículo como caminho em construção, não algo pronto e acabado, documento formal que se faz para ter à disposição nos arquivos escolares. 
O currículo deve ser um registro que nasce de nossas inquietações, perguntas e propósitos, como caminho que não se trilha sozinho. Assim, a construção de um currículo pressupõe trabalho coletivo, estudo e reflexão. De acordo com Barbosa (2009, p. 57),

A projeção e elaboração de um currículo é importante porque nos faz refletir e avaliar nossas escolhas, nossas concepções de conhecimento, infância e criança, reorientando nossas opções. Essas são sempre históricas, sempre redutoras diante da imprevisibilidade que é viver no mundo. Isto é, o currículo diz respeito a acontecimentos cotidianos que não podem ser objetivamente, determinados, tendo em vista a sua abertura ao inesperado.

Um processo em construção que deve evidenciar concepções de criança, de aprendizagem e desenvolvimento, de escola da infância, suscitando um diálogo permanente entre a teoria e o fazer educativo num processo dinâmico. 0 trabalho coletivo, a observação das crianças, as características de cada contexto escolar, bem como a nossa leitura de mundo, as teorias e as nossas concepções são aspectos importantes no processo de construção de um currículo.

Quando dizemos de nossa abertura ao inesperado, trazemos a característica da flexibilidade diante da necessidade de se repensar o currículo, a postura de aprendiz do educador, a abertura para o inesperado. Esse repensar pode ser consequência de uma situação do cotidiano, de uma pergunta de uma criança, de um fato ocorrido na comunidade, enfim de alguma situação que suscita uma nova reflexão sobre as nossas concepções e/ou sobre questões metodológicas ou ainda sobre aspectos relacionados à organização da escola.

Cabe acrescentar, como aspecto de fundamental importância, que o currículo na Educação Infantil não está centrado em conteúdos e informações, mas centrado na criança. A Educação Infantil reúne as dimensões do cuidado e da educação. O currículo marca o caráter de intencionalidade do trabalho educativo com as crianças.

O currículo busca articular as experiências e os saberes das crianças com os conhecimentos que fazem parte do patrimônio cultural, artístico, científico e tecnológico da sociedade por meio de práticas planejadas e permanentemente avaliadas que estruturam o cotidiano das instituições. (OLIVEIRA, 2010, p. 4). 
Ao analisarmos a BNCC, nos perguntamos qual a concepção de currículo defendida no documento. A organização curricular da Educação Infantil na BNCC está estruturada em cinco campos de experiências/objetivos de aprendizagem e de desenvolvimento. De acordo com Lopes e Sobral (2014, p. 97),

[...] um currículo por experiências se ancora, principalmente, nas teorizações de Dewey em textos publicados, como por exemplo: A Criança e o Currículo, e que considera que as experiências são plurais, globais e se relacionam com os contextos de vida cotidiana [...].

Acreditamos que esse foi o sentido buscado na BNCC ao propor um arranjo curricular organizado em cinco campos de experiências na Educação Infantil. Tecemos nossas observações sobre cada campo de experiências, bem como buscamos identificar como os campos de experiências entendem a criança e a relação aprendizagem e desenvolvimento.

\section{CAMPO DE EXPERIÊNCIAS: O EU, O OUTRO E O NÓS}

O foco central desse campo de experiências está na interação social como processo educativo, pois, de acordo com a BNCC (BRASIL, 2017, p. 36), "É na interação com os pares e com os adultos que as crianças vão constituindo um modo próprio de agir, sentir e pensar e vão descobrindo que existem outros modos de vida, pessoas diferentes, com outros pontos de vista".

Ao analisarmos o quadro que apresenta os objetivos de aprendizagem desse campo de experiências, percebemos que foi pensada uma gênese, isto é, a origem e a história da interação social pela criança. 
Figura 1 - Campo de experiências: o eu, o outro e o nós

\begin{tabular}{|c|c|c|}
\hline $\begin{array}{l}\text { (ElO1EOO3) } \\
\text { Interagir com criancas } \\
\text { da mesma faixa etária } \\
\text { e adultos ao explorar } \\
\text { materiais, objetos, } \\
\text { brinquedos. }\end{array}$ & $\begin{array}{l}\text { (ElO2EOO3) } \\
\text { Compartilhar os objetos e } \\
\text { os espaços com crianças } \\
\text { da mesma faixa etária e } \\
\text { adultos. }\end{array}$ & $\begin{array}{l}\text { (ElO3EOO3) } \\
\text { Ampliar as relaçōes } \\
\text { interpessoais, } \\
\text { desenvolvendo atitudes de } \\
\text { participação e cooperaçăo. }\end{array}$ \\
\hline $\begin{array}{l}\text { (ElO1EO04) } \\
\text { Comunicar necessidades, } \\
\text { desejos e emoḉes, } \\
\text { utilizando gestos, } \\
\text { balbucios, palavras. }\end{array}$ & $\begin{array}{l}\text { (ElO2EOO4) } \\
\text { Comunicar-se com os } \\
\text { colegas e os adultos. } \\
\text { buscando compreendê-los } \\
\text { e fazendo-se compreender. }\end{array}$ & $\begin{array}{l}\text { (EIO3EOO4) } \\
\text { Comunicar suas ideias } \\
\text { e sentimentos com } \\
\text { desenvoltura a pessoas e } \\
\text { grupos diversos. }\end{array}$ \\
\hline $\begin{array}{l}\text { (EIO1EOO5) } \\
\text { Reconhecer as } \\
\text { sensaçōes de seu corpo } \\
\text { em momentos de } \\
\text { alimentaço, higiene, } \\
\text { brincadeira e descanso. }\end{array}$ & $\begin{array}{l}\text { (EIO2EOO5) } \\
\text { Habituar-se a práticas } \\
\text { de cuidado com o corpo, } \\
\text { desenvolvendo noçóes de } \\
\text { bem-estar. }\end{array}$ & $\begin{array}{l}\text { (EIO3EOO5) } \\
\text { Adotar hábitos de } \\
\text { autocuidado, valorizando } \\
\text { atitudes relacionadas } \\
\text { a higiene, alimentação, } \\
\text { conforto e cuidados com a } \\
\text { aparência. }\end{array}$ \\
\hline
\end{tabular}

\section{CAMPO DE EXPERIÊNCIAS "O EU, O OUTRO E O NÓS"}

\section{OBJETIVOS DE APRENDIZAGEM E DESENVOLVIMENTO}

\begin{tabular}{|c|c|c|}
\hline $\begin{array}{l}\text { Crianças de zero a } 1 \text { ano e } \\
6 \text { meses }\end{array}$ & $\begin{array}{l}\text { Crianças de } 1 \text { ano e } 7 \\
\text { moses a } 3 \text { anos e } 11 \text { meses }\end{array}$ & $\begin{array}{l}\text { Criancas de } 4 \text { anos a } 5 \text { anos } \\
\text { e } 11 \text { meses }\end{array}$ \\
\hline $\begin{array}{l}\text { (EIO1EOO1) } \\
\text { Perceber que suas acōes } \\
\text { têm efeitos nas outras } \\
\text { crianças e nos adultos. }\end{array}$ & $\begin{array}{l}\text { (EIO2EOO1) } \\
\text { Demonstrar atitudes de } \\
\text { cuidado e solidariedade na } \\
\text { interaço com crianças e } \\
\text { adultos. }\end{array}$ & $\begin{array}{l}\text { (ElO3EOO1) } \\
\text { Demonstrar empatia pelos } \\
\text { outros, percebendo que } \\
\text { as pessoas têm diferentes } \\
\text { sentimentos, necessidades } \\
\text { e maneiras de pensar e agir. }\end{array}$ \\
\hline $\begin{array}{l}\text { (EIOIEOO2) } \\
\text { Perceber as possibilidades } \\
\text { e os limites de seu } \\
\text { corpo nas brincadeiras } \\
\text { e interacöes das quais } \\
\text { participa. }\end{array}$ & $\begin{array}{l}\text { (EIO2EOO2) } \\
\text { Demonstrar imagem } \\
\text { positiva de si e confianca } \\
\text { em sua capacidade para } \\
\text { enfrentar dificuldadese } \\
\text { desafios. }\end{array}$ & $\begin{array}{l}\text { (EIO3EOO2) } \\
\text { Atuar de maneira } \\
\text { independente, com } \\
\text { confiança em suas } \\
\text { capacidades, reconhecendo } \\
\text { suas conquistas e } \\
\text { limitaçōes. }\end{array}$ \\
\hline
\end{tabular}




\begin{tabular}{|c|c|c|}
\hline $\begin{array}{l}\text { (EIO1EO06) } \\
\text { Construir formas de } \\
\text { interaço com outras } \\
\text { crianças da mesma } \\
\text { faixa etária e adultos, } \\
\text { adaptando-se ao convivio } \\
\text { social. }\end{array}$ & $\begin{array}{l}\text { (EIO2EOO6) } \\
\text { Respeitar regras básicas } \\
\text { de convivio social nas } \\
\text { interaçóes e brincadeiras. }\end{array}$ & $\begin{array}{l}\text { (ElO3EO06) } \\
\text { Compreender a necessidade } \\
\text { das regras no convivio } \\
\text { social, nas brincadeiras } \\
\text { e nos jogos com outras } \\
\text { crianças. }\end{array}$ \\
\hline $\begin{array}{l}\text { (ElO1EOO7) } \\
\text { Demonstrar sentimentos } \\
\text { de afeiço pelas pessoas } \\
\text { com as quais interage. }\end{array}$ & $\begin{array}{l}\text { (EIO2EOO7) } \\
\text { Valorizar a diversidade ao } \\
\text { participar de situaços de } \\
\text { convivio com diferenças. }\end{array}$ & $\begin{array}{l}\text { (EIO3EOO7) } \\
\text { Manifestar oposiç̄o } \\
\text { a qualquer forma de } \\
\text { discriminaço. }\end{array}$ \\
\hline $\begin{array}{l}\text { (EIO1EOOB) } \\
\text { Desenvolver confianca em } \\
\text { si, em seus pares e nos } \\
\text { adultos em situaçós de } \\
\text { interaç̄o. }\end{array}$ & $\begin{array}{l}\text { (EIO2EOOB) } \\
\text { Resolver conflitos nas } \\
\text { interacöes e brincadeiras, } \\
\text { com a orientaçăo de um } \\
\text { adulto. }\end{array}$ & $\begin{array}{l}\text { (EIO3EOOB) } \\
\text { Usar estratégias pautadas } \\
\text { no respeito mútuo para } \\
\text { lidar com conflitos nas } \\
\text { interacōes com criancas } \\
\text { e adultos. }\end{array}$ \\
\hline
\end{tabular}

Fonte: Base Nacional Curricular da Educação Infantil (BRASIL, 2017).

Tendo como concepção de criança um sujeito histórico-social, nos preocupa a interação social concebida de modo linear, gradativo, o que retira o caráter dinâmico da constituição do sujeito a partir das interações sociais. Quando analisamos, verticalmente, os objetivos pensados para as crianças de zero a um ano e seis meses, nos perguntamos qual é realmente a concepção de criança defendida na BNCC. Ao observamos os três primeiros objetivos, identificamos uma concepção de criança que caminha do nível individual para o nível social. Por exemplo em dois trechos: Perceber que suas ações têm efeitos nas outras crianças e nos adultos. Perceber as possibilidades e os limites de seu corpo nas brincadeiras e interações das quais participa. A criança irá balizar nessa idade as consequências de suas atitudes?

O texto da BNCC não evidencia uma ordem para o trabalho com os objetivos pensados para cada faixa etária, mas ao analisarmos os objetivos pensados para as crianças de 0 a 1 ano e 6 meses nesse campo de experiências, identificamos a direção do desenvolvimento, do indivíduo para o social. Nos objetivos elencados para as crianças de 1 ano e sete meses a 3 anos e 11 meses, identificamos a concepção de um sujeito que já é social e que se espera dessa criança boas atitudes para um bom convívio escolar em afirmações como: Demonstrar atitudes de cuidado 
e solidariedade na interação com crianças e adultos. Compartilhar os objetos e os espaços com crianças da mesma faixa etária e adultos. Respeitar regras básicas de convívio social nas interações e brincadeiras. Chama-nos também a atenção a colocação do seguinte objetivo: Resolver conflitos nas interações e brincadeiras com a orientação de um adulto. Esse objetivo destinar-se-ia aos educadores ou às crianças?

Identificamos que os objetivos de desenvolvimento e aprendizagem buscaram englobar as dimensões de educação e cuidado, como em: Habituar-se a práticas de cuidado com o corpo desenvolvendo noções de bem-estar. Mas o que significaria "noções de bem-estar"?

Os objetivos pensados para crianças de 4 a 5 anos e 11 meses têm como foco a postura esperada pelas crianças nessa faixa etária. Demonstrar empatia pelos outros, percebendo que as crianças têm diferentes sentimentos, necessidades e maneiras de pensar e agir. As crianças só expressam empatia? Não seria, igualmente, importante a criança expressar suas dificuldades de convivência? As crianças só percebem as diferenças a partir de 4 anos? Adotar hábitos de autocuidado, valorizando atitudes relacionadas a higiene, alimentação, conforto e cuidados com a aparência. O que seriam atitudes relacionadas ao conforto? Enfim, constatamos que os objetivos para as três faixas etárias trazem centralmente o cuidado com o próprio corpo e objetivos relacionados à interação social, ao amadurecimento de comportamentos esperados para o bom convívio social. Sem minimizar a importância de se considerar esses aspectos, acreditamos que esse campo de experiências precisa ser enriquecido quanto às possibilidades de abordagem curricular relacionadas à natureza social, cerne desse campo de experiências.

Sentimos falta da busca pela ampliação do universo cultural da criança, da ênfase ao trabalho com elementos da cultura, da abordagem de temas sociais. Consideramos que a ausência dessa abordagem esvaziou o campo de experiências e não conseguiu o diálogo com a concepção de criança defendida na introdução do documento.

\section{CAMPO DE EXPERIÊNCIAS: CORPO, GESTOS E MOVIMENTOS}

Em relação a esse campo de experiências, a BNCC (BRASIL, 2017, p. 36) afirma que: 
Com o corpo (por meio dos sentidos, movimentos impulsivos ou intencionais, coordenados ou espontâneos). As crianças, desde cedo, exploram o mundo, o espaço e os objetos do seu entorno, estabelecem relações, expressam-se, brincam e produzem conhecimentos sobre si, sobre o outro, sobre o universo social e cultural, tornando-se, progressivamente, conscientes dessa corporeidade.

O eixo central desse campo de experiências é o corpo, sendo que as diferentes linguagens, as possibilidades de movimento, as funções corporais se constituem como eixo desse campo. No entanto os objetivos mencionados são insuficientes para o cumprimento do que se pretende com esse campo.

Figura 2 - Campo de experiências: corpo, gestos e movimentos

\section{CAMPO DE EXPERIÊNCIAS "CORPO, GESTOS E MOVIMENTOS"}

\section{OBJETIVOS DE APRENDIZAGEM E DESENVOLVIMENTO}

\begin{tabular}{|c|c|c|}
\hline $\begin{array}{l}\text { Crianças de zero a } \\
\text { lano e } 6 \text { meses }\end{array}$ & $\begin{array}{l}\text { Crianças de } 1 \text { ano e } 7 \text { meses } \\
\text { a } 3 \text { anos e } 11 \text { meses }\end{array}$ & $\begin{array}{l}\text { Crianças de } 4 \text { anos a } \\
5 \text { anos e } 11 \text { meses }\end{array}$ \\
\hline $\begin{array}{l}\text { (EIO1CG01) } \\
\text { Movimentar as partes } \\
\text { do corpo para exprimir } \\
\text { corporalmente emocōes, } \\
\text { necessidades e desejos. }\end{array}$ & $\begin{array}{l}\text { (EIO2CGO1) } \\
\text { Apropriar-se de gestos e } \\
\text { movimentos de sua cultura } \\
\text { no cuidado de si e nos } \\
\text { jogos e brincadeiras. }\end{array}$ & $\begin{array}{l}\text { (EIO3CGO1) } \\
\text { Movimentar-se de forma } \\
\text { adequada, ao interagir } \\
\text { com colegas e adultos em } \\
\text { brincadeiras e atividades. }\end{array}$ \\
\hline $\begin{array}{l}\text { (EIO1CGO2) } \\
\text { Ampliar suas possibilidades } \\
\text { de movimento em } \\
\text { espaços que possibilitem } \\
\text { exploraçōes diferenciadas. }\end{array}$ & $\begin{array}{l}\text { (ElO2CGO2) } \\
\text { Explorar formas de } \\
\text { deslocamento no espaço } \\
\text { (pular, saltar, dançar). } \\
\text { combinando movimentos e } \\
\text { seguindo orientaçōes. }\end{array}$ & $\begin{array}{l}\text { (ElO3CGO2) } \\
\text { Criar movimentos, } \\
\text { gestos, olhares, mimicas } \\
\text { e sons com o corpo em } \\
\text { brincadeiras, jogos e } \\
\text { atividades artisticas como } \\
\text { danç, teatro e música. }\end{array}$ \\
\hline
\end{tabular}




\begin{tabular}{|c|c|c|}
\hline $\begin{array}{l}\text { (ElO1CG03) } \\
\text { Experimentar as } \\
\text { possibilidades de seu } \\
\text { corpo nas brincadeiras e } \\
\text { interaçōes em ambientes } \\
\text { acolhedores e desafiantes. }\end{array}$ & $\begin{array}{l}\text { (El02CG03) } \\
\text { Fazer uso de suas } \\
\text { possibilidades corporais, } \\
\text { ao se envolver em } \\
\text { brincadeiras e atividades } \\
\text { de diferentes naturezas. }\end{array}$ & $\begin{array}{l}\text { (ElO3CG03) } \\
\text { Demonstrar controle e } \\
\text { adequaç̌o do uso de seu } \\
\text { corpo em momentos de } \\
\text { cuidado, brincadeiras e } \\
\text { jogos, escuta e reconto } \\
\text { de histórias, atividades } \\
\text { artisticas, entre outras } \\
\text { possibilidades. }\end{array}$ \\
\hline $\begin{array}{l}\text { (ElO1CG04) } \\
\text { Participar do cuidado do } \\
\text { seu corpo e da promoç̃o } \\
\text { do seu bem-estar. }\end{array}$ & $\begin{array}{l}\text { (ElO2CG04) } \\
\text { Demonstrar progressiva } \\
\text { independência no cuidado } \\
\text { do seu corpo. }\end{array}$ & $\begin{array}{l}\text { (ElO3CG04) } \\
\text { Demonstrar valorizaçäo } \\
\text { das caracteristicas de } \\
\text { seu corpo, nas diversas } \\
\text { atividades das quais } \\
\text { participa e em momentos } \\
\text { de cuidado de si e do } \\
\text { outro. }\end{array}$ \\
\hline $\begin{array}{l}\text { (ElO1CGO5) } \\
\text { Imitar gestos, sonoridades } \\
\text { e movimentos de outras } \\
\text { criancas, adultos e animais. }\end{array}$ & $\begin{array}{l}\text { (EIO2CGOS) } \\
\text { Deslocar seu corpo no } \\
\text { espaço, orientando-se por } \\
\text { noçōes como em frente, } \\
\text { atrás, no alto, embaixo, } \\
\text { dentro, fora etc. }\end{array}$ & $\begin{array}{l}\text { (Elo3CG05) } \\
\text { Criar com o corpo formas } \\
\text { diversificadas de expressāo } \\
\text { de sentimentos, sensaçōes } \\
\text { e emoçס̄es, tanto nas } \\
\text { situaçōes do cotidiano } \\
\text { quanto em brincadeiras, } \\
\text { dança, teatro, música. }\end{array}$ \\
\hline $\begin{array}{l}\text { (EIOICG06) } \\
\text { Utilizar os movimentos } \\
\text { de preensJo, encaixe e } \\
\text { lancamento, ampliando } \\
\text { suas possibilidades de } \\
\text { manuseio de diferentes } \\
\text { materiais e objetos. }\end{array}$ & $\begin{array}{l}\text { (EIO2CG06) } \\
\text { Desenvolver } \\
\text { progressivamente as } \\
\text { habilidades manuais, } \\
\text { adquirindo controle para } \\
\text { desenhar, pintar, rasgar, } \\
\text { folhear, entre outros. }\end{array}$ & $\begin{array}{l}\text { (ElO3CGO6) } \\
\text { Coordenar com precisaso e } \\
\text { eficiência suas habilidades } \\
\text { motoras no atendimento } \\
\text { a seus interesses } \\
\text { e necessidades de } \\
\text { representaç̃o gráfica. }\end{array}$ \\
\hline
\end{tabular}

Fonte: Base Nacional Curricular da Educação Infantil (BRASIL, 2017).

Os objetivos pensados para as crianças de zero a 1 ano e seis meses relacionam-se aos cuidados e movimentos do próprio corpo, dos grandes músculos e também dos pequenos músculos. Vejamos o objetivo Participar do cuidado com o seu corpo e da promoção de seu bem-estar", para a criança de zero a um ano e seis meses. O que vem a ser o bem-estar? E qual seria a expectativa de 
participação da criança nessa idade com o cuidado de seu corpo nessa faixa etária?

No campo da expressão aparece a imitação como uma possiblidade para crianças nessa faixa etária: Imitar gestos, sonoridades e movimentos de outras crianças, adultos e animais. Por que delimitar? E a descoberta de sons do próprio corpo e sons da natureza? Em relação aos objetivos pensados para as crianças de 1 ano e sete meses a 3 anos e 11 meses encontramos, centralmente, o cuidado e movimento do próprio corpo e um objetivo com foco na expressão: Apropriar-se de gestos e movimentos de sua cultura no cuidado de si e nos jogos e brincadeiras. O que se pretende quando se busca a apropriação de gestos? Seria a aprendizagem de gestos presentes na nossa cultura? Explorar formas de deslocamento no espaço, pular, saltar, dançar) combinando movimentos e seguindo orientações. Seria expressão ou correspondência a comandos? Desenvolver progressivamente as habilidades manuais adquirindo controle para desenhar, pintar, rasgar, folhear, entre outros. Habilidades manuais, controle ou expressão?

Quanto aos objetivos pensados para as crianças de 4 anos a 5 anos e 11 meses, questionamos alguns objetivos. Movimentar -se de forma adequada, ao interagir com colegas e adultos em brincadeiras e atividades. O que vem a ser movimentar-se de forma adequada? Seria movimentar-se com equilíbrio? Demonstrar valorização das características de seu corpo, nas atividades das quais participa e em momentos de cuidado de si e do corpo. O que significa valorização das características de seu corpo? Coordenar com precisão e eficiência suas habilidades motoras no atendimento a seus interesses e necessidades e representação gráfica. O que se caracteriza por precisão e eficiência de habilidades? Será que a criança tem interesse e necessidade de representar graficamente ou apenas cumpre o que é estabelecido pela escola?

Consideramos que os objetivos apresentados para as diferentes faixas etárias não são suficientes para garantir o foco pensado para esse campo de experiências. Ao se referir às diferentes linguagens, os objetivos mencionados não suscitam um trabalho efetivo relacionado à expressão cênica, à expressão musical e à expressão plástica. No que se refere aos movimentos do próprio corpo, também pontuamos que os objetivos são vagos e insuficientes como para a criança tomar consciência de sua corporeidade. (BNCC, 2017, p.37). Sentimos falta de objetivos relacionados ao esquema corporal, à tonicidade, à lateralidade e ao equilíbrio. 
Ao analisarmos esse campo de experiências, percebemos que, embora aborde as dimensões do cuidado, da educação do próprio corpo e das diferentes linguagens, ao reunir corpo, movimento e expressão, o texto apresenta lacunas em aspectos que deveriam ser explorados no contexto da Educação Infantil.

\section{CAMPO DE EXPERIÊNCIAS: TRAÇOS, SONS, CORES E FORMAS}

Apresenta-se como eixo central desse campo de experiências a expressão da criança nas mais diferentes linguagens.

Conviver com diferentes manifestações artísticas, culturais e científicas, locais e universais, no cotidiano da instituição escolar, possibilita às crianças, por meio de experiências diversificadas vivenciar diversas formas de expressão e linguagens. (BRASIL, 2017, p. 37).

Figura 3 - Campo de experiências: traços, sons, cores e formas

CAMPO DE EXPERIÊNCIAS "TRAÇOS, SONS, CORES E FORMAS"

\begin{tabular}{|c|c|c|}
\hline $\begin{array}{l}\text { Crianças de zero a } \\
1 \text { ano e } 6 \text { meses }\end{array}$ & $\begin{array}{l}\text { Crianças de } 1 \text { ano e } 7 \text { meses } \\
\text { a } 3 \text { anos e } 11 \text { moses }\end{array}$ & $\begin{array}{l}\text { Criancas de } 4 \text { anos a } \\
5 \text { anos e } 11 \text { meses }\end{array}$ \\
\hline $\begin{array}{l}\text { (EIOITSO1) } \\
\text { Explorar sons produzidos } \\
\text { com o próprio corpo e com } \\
\text { objetos do ambiente. }\end{array}$ & $\begin{array}{l}\text { (EIO2TSO1) } \\
\text { Criar sons com materiais, } \\
\text { objetos e instrumentos } \\
\text { musicais, para acompanhar } \\
\text { diversos ritmos de música. }\end{array}$ & $\begin{array}{l}\text { (EIO3TSO1) } \\
\text { Utilizar sons produzidos } \\
\text { por materiais, objetos e } \\
\text { instrumentos musicais } \\
\text { durante brincadeiras de } \\
\text { faz de conta, encenacöes, } \\
\text { criacóes musicais, festas. }\end{array}$ \\
\hline
\end{tabular}




\section{(EIO1TSO2)}

Traçar marcas gráficas, em diferentes suportes, usando instrumentos riscantes e tintas.

\section{(EI02TS02)}

Utilizar diferentes materiais, suportes e procedimentos para grafar, explorando cores, texturas, superficies, planos, formas e volumes.

\section{(E102TS03)}

Expressar-se por meio de linguagens como a do desenho, da música, do movimento corporal, do teatro.

\section{Utilizar materiais variados com possibilidades de manipulaçð̄o (argila, massa de modelar), criando objetos tridimensionais.}

\section{(EIO1TS04)}

Explorar diferentes fontes sonoras e materiais para acompanhar brincadeiras cantadas, cançóes, músicas e melodias.

\section{(EIOITSO5)}

Imitar gestos, movimentos, sons, palavras de outras criancas e aduitos, animais, objetos e fenomenos da natureza.

\section{(EIO2TSO4)}

Utilizar diferentes fontes sonoras disponiveis no ambiente em brincadeiras cantadas, canç̌́es, músicas e melodias.

\section{(EIO2TSO5)}

Imitar e criar movimentos próprios, em danças, cenas de teatro, narrativas e músicas.

\section{(EIO3TSO2)}

Expressar-se livremente por meio de desenho, pintura, colagem. dobradura e escultura, criando producós bidimensionais e tridimensionais.

\section{(EIO3TSO3)}

Apreciar e participar de apresentaçóes de teatro. música, dança, circo, recitacalo de poemas e outras manifestaçōes artisticas.

\section{(EIO3TSO4)}

Reconhecer as qualidades do som (intensidade. duraçăo, altura e timbre). utilizando-as em suas produços sonoras e ao ouvir músicas e sons.

\section{(E103TSO5)}

Reconhecer e ampliar possibilidades expressivas do seu corpo por meio de elementos da dança.

Fonte: Base Nacional Curricular da Educação Infantil (BRASIL, 2017).

Ao analisarmos horizontalmente o quadro de objetivos de aprendizagem e desenvolvimento, constatamos que inicialmente se buscou pensar em um mesmo aspecto para diferentes faixas etárias. Nesse sentido, o primeiro objetivo se relaciona à expressão musical para as três faixas etárias; o segundo objetivo, às marcas gráficas para as crianças até um ano e seis meses; depois, para crianças até 3 anos e 11 meses; o quarto objetivo, à expressão musical para as três faixas etárias; e o quinto objetivo, à expressão cênica.

Podemos identificar uma gênese, ou seja, uma concepção que prevê o desenvolvimento de modo gradativo considerando cada faixa etária. Constatamos esse aspecto em outros campos de experiências, o que nos faz perguntar qual 
seria a concepção de criança, de desenvolvimento e de aprendizagem. Essa linearidade teria sido pensada a partir de quais pressupostos e estudos sobre o desenvolvimento? Por outro lado, se analisarmos os objetivos verticalmente, por faixa etária, constatamos o caminho que foi pensado para a criança percorrer na Educação Infantil. No que se refere a esse campo de experiências, inferimos que a criança terá oportunidades diversas de expressão em cada faixa etária, o que consideramos aspecto significativo e relevante para seu desenvolvimento.

Temos consciência que a divisão em campos de experiências constitui-se em uma organização didática, já que na prática entendemos que a integração das áreas do conhecimento é um dos princípios metodológicos do trabalho na Educação Infantil. Considerando que a BNCC fez essa opção didática para a divisão dos campos das experiências, acreditamos que seria mais adequado e coerente que as diferentes linguagens fossem discutidas nesse campo de experiências: Traços, Sons, Cores e Formas. A referência às linguagens, ainda que com outros objetivos no campo de experiências, Corpo, Gestos e Movimentos, se caracteriza de modo superficial.

\section{CAMPO DE EXPERIÊNCIAS: ORALIDADE E ESCRITA}

O campo de experiências Oralidade e Escrita tem recebido críticas de estudiosos da área. As alterações propostas na versão 3 da BNCC foram analisadas por uma equipe de educadores que redigiu, inclusive, um documento intitulado: Posicionamento do Projeto Leitura e Escrita na Educação Infantil, em relação à terceira visão da BNCC.

De acordo com a BNCC (BRASIL, 2017, p. 37-8)

A Educação Infantil é a etapa em que as crianças estão se apropriando da língua oral e, por meio de variadas situações nas quais podem falar e ouvir, vão ampliando e enriquecendo seus recursos de expressão e compreensão, o seu vocabulário, o que possibilita a internalização de estruturas linguísticas mais complexas [...] Nesse convívio com textos escritos, as crianças vão construindo hipóteses sobre a escrita que se revelam, inicialmente, em rabiscos e garatujas e, à medida que vão conhecendo letras, em escritas espontâneas, não convencionais, mas já indicativas da compreensão da escrita como representação da oralidade.

Uma das críticas se refere a uma questão conceitual presente no texto da BNCC: a escrita representa a língua, e não a oralidade. Uma outra questão 
mencionada nesse posicionamento em relação à base se refere ao convívio das crianças com textos escritos e à construção de hipóteses. Os autores alertam que não há construção de hipóteses apenas pelo convívio, pois isso requer ensino intencional. Esses dois aspectos precisam ser compreendidos para que se possa pensar o caminho metodológico que será proposto para a criança.

O campo de experiências Oralidade e Escrita é o que apresenta o maior número de objetivos. Sabemos o quanto essa área tem sido discutida, e essa temática na relação com o papel da Educação Infantil tem diferentes olhares.

Segue o quadro com os objetivos para tecermos nossas considerações.

Figura 4 - Campo de experiências: oralidade e escrita CAMPO DE EXPERIÊNCIAS "ORALIDADE E ESCRITA"

\begin{tabular}{|c|c|c|}
\hline $\begin{array}{l}\text { Criancas de zero a } \\
1 \text { ano e } 6 \text { meses }\end{array}$ & $\begin{array}{l}\text { Crianças de } 1 \text { ano e } 7 \text { meses } \\
\text { a } 3 \text { anos o } 11 \text { meses }\end{array}$ & $\begin{array}{l}\text { Criancas de } 4 \text { anos a } \\
5 \text { anos e } 11 \text { meses }\end{array}$ \\
\hline $\begin{array}{l}\text { (Elo1OEO1) } \\
\text { Reconhecer quando é } \\
\text { chamado por seu nome e } \\
\text { reconhecer os nomes de } \\
\text { pessoas com quem convive. }\end{array}$ & $\begin{array}{l}\text { (EIO2OEO1) } \\
\text { Dialogar com criancas e } \\
\text { adultos, expressando seus } \\
\text { desejos, necessidades, } \\
\text { sentimentos e opinioles. }\end{array}$ & $\begin{array}{l}\text { (ElozOEO1) } \\
\text { Expressar ideias, desejos } \\
\text { e sentimentos sobre suas } \\
\text { vivências, por meio da } \\
\text { linguagem oral e escrita } \\
\text { (oscrita espontånea), do } \\
\text { fotos, desenhos e outras } \\
\text { formas de expressắa. }\end{array}$ \\
\hline $\begin{array}{l}\text { (EIO1OEO2) } \\
\text { Demonstrar interesse ao } \\
\text { ouvir a leitura de poemas e } \\
\text { a aprosentaço de músicas. }\end{array}$ & $\begin{array}{l}\text { (EIO2OEO2) } \\
\text { Identificar e criar diferentes } \\
\text { sons e reconhecer rimas e } \\
\text { aliteracoes em cantigas de } \\
\text { roda e textos poéticos. }\end{array}$ & $\begin{array}{l}\text { (EIO3OEO2) } \\
\text { Inventar brincadeiras } \\
\text { cantadas, poemas e } \\
\text { cançóes, criando rimas, } \\
\text { aliteraçōes o ritmos. }\end{array}$ \\
\hline
\end{tabular}




\section{(E101OEO3)}

Demonstrar interesse ao ouvir histórias lidas ou contadas, observando ilustraç̋es e os movimentos de leitura do adulto-leitor (modo de segurar o portador e de virar as påginas).

\section{(E101OE04)}

Reconhecer elementos das ilustraç̄es de histórias, apontando-os, a pedido do adulto-leitor.

\section{(EIO2OEO3)}

Demonstrar interesse e atençâo ao ouvir a leitura de histórias e outros textos, diferenciando escrita de ilustraçóes. e acompanhando, com orientaç̋o do adulto- leitor, a direçåo da leitura (de cima para baixo, da esquerda para a direita).

ler histórias e ao cantar.

\section{(EIO1OEO6)}

Comunicar-se com outras pessoas usando movimentos, gestos, balbucios, fala e outras formas de expressăo.

\section{(EIO1OEO7)}

Conhecer e manipular materiais impressos e audiovisuais em diferentes portadores (livro, revista, gibi, jornal, cartaz, CD. tablet etc.).

\section{(EIO1OEOB)}

Ter contato com diferentes gêneros textuais (poemas, fábulas, contos, receitas. quadrinhos, anùncios etc.).

\section{(EIO1OEO9)}

Ter contato com diferentes instrumentos e suportes de escrita.

\section{(EIO2OEO6)}

Criar e contar histórias oralmente, com base em imagens ou temas sugeridos.

\section{(EIO3OEO3)}

Escolher e folhear livros, procurando orientar-se por temas e ilustraçōes e tentando identificar palavras conhecidas.

\section{(E102OE04)}

Formular e responder perguntas sobre fatos da história narrada, identificando cenários. personagens e principais acontecimentos.

\section{(EIO2OEO5)}

Relatar experiências e fatos acontecidos, histórias ouvidas, filmes ou peças teatrais assistidos etc.

\section{(E1030E04)}

Recontar histórias ouvidas - planejar coletivamente roteiros de vídeos e de encenaços, definindo os contextos, os personagens, a estrutura da história.

\section{(EIO3OEO5)}

Recontar histórias ouvidas para produçáo de reconto escrito, tendo o professor como escriba.

\section{(EIO3OEO6)}

Produzir suas próprias histórias orais e escritas (escrita espontânea), em situações com funçäo social significativa.

\section{(EI03OEO7)}

Levantar hipóteses sobre gêneros textuais veiculados em portadores conhecidos, recorrendo a estratégias de observação gráfica e de leitura. caracteristicas graficas.

\section{(EIO2OEO8)}

Ampliar o contato com diferentes gêneros textuais (parlendas, histórias de aventura, tirinhas, cartazes de sala, cardápios, noticias etc).

\section{(EIO2OEO9)}

Manusear diferentes instrumentos e suportes de escrita para desenhar. traçar letras e outros sinais gráficos.

\section{(EIO3OEO8)}

Identificar gêneros textuais mais frequentes, recorrendo a estratégias de configuraç̄o gräfica do portador e do texto e ilustraços nas páginas.

\section{(EIO3OEO9)}

Levantar hipóteses em relaçăo a linguagem escrita, realizando registros de palavras e textos, por meio de escrita espontânea.

Fonte: Base Nacional Curricular da Educação Infantil (BRASIL, 2017). 
Nos objetivos pensados para as crianças de zero a 1 ano e seis meses, apontamos aqueles relacionados ao reconhecimento do próprio nome, à literatura infantil, à comunicação com outras pessoas e ao contato com diferentes gêneros textuais e diferentes suportes de escrita. Estamos nos referindo a crianças até um ano e meio e nos perguntamos o que significa ter contato com diferentes gêneros textuais e ter contato com diferentes suportes de escrita. Não há clareza na definição desses objetivos.

Em relação aos objetivos pensados para as crianças de 1 ano e sete meses a 3 anos e onze meses, estes são apresentados relacionados à comunicação, à identificação de rimas, à criação e compreensão de histórias, ao reconhecimento da função social de diferentes portadores textuais, ao contato com diferentes gêneros textuais e ao manuseio de diferentes instrumentos e suportes de escrita para desenhar e traçar letras e sinais gráficos. Questionamos novamente o que seria esse contato e o que seria esse manuseio de diferentes gêneros e suportes. Não há também clareza no percurso que será proposto à criança para alcançar os objetivos.

Para as crianças de 4 anos a 5 anos e 11 meses são apresentados objetivos relacionados à expressão de ideias, à invenção de brincadeiras com rimas, à produção e reconto de histórias, ao levantamento de hipóteses sobre gêneros textuais e sobre a linguagem escrita, incluindo registros por meio da escrita espontânea. Questionamos quais seriam as expectativas relacionadas ao objetivo de levantar hipóteses sobre gêneros textuais veiculados a suportes conhecidos.

No campo de Experiências Oralidade e Escrita, também verificamos uma tentativa de se organizar o objetivo para as três faixas etárias, graduando a complexidade da proposta. Identificamos que não há clareza do que se constitui objetivo e do que se constitui atividade pedagógica. A BNCC não fez nenhuma referência teórica ao caminho que a criança percorre na construção dos processos de leitura e escrita, de maneira que poderia ser entendida apenas a atividades desvinculadas do processo de desenvolvimento da criança.

Cabe enfatizar que os aspectos metodológicos precisam ser pensados, planejados, criados a partir da compreensão de conceitos e aspectos teóricos. Entretanto o que ressalta são as atividades sem uma compreensão do que de fato se constitui uma atividade significativa no processo de desenvolvimento da criança. 
Outra questão merecedora de questionamentos se refere à elucidação de objetivos de aprendizagem e de desenvolvimento. Aprendizagem e desenvolvimento são entendidos da mesma forma? Há objetivos para o desenvolvimento e objetivos pensados para a aprendizagem? Essa dúvida ou questionamento também envolve os outros campos de experiências.

\section{CAMPO DE EXPERIÊNCIAS: ESPAÇOS, TEMPOS, QUANTIDADES, RELAÇÕES E TRANSFORMAÇÕES}

A busca pela compreensão do mundo faz parte do universo infantil, foi e continua sendo uma questão estudada por teóricos vinculados a diferentes matrizes teóricas. Nesse campo de experiências, o foco está nos aspectos que se relacionam ao mundo físico e sociocultural. Conceitos relacionados à matemática, conceitos científicos, conceitos relacionados aos diferentes modos de vida consistem no eixo desse campo de experiências.

As crianças vivem inseridas em espaços e tempos de diferentes dimensões, em um mundo constituído de fenômenos naturais e socioculturais. Desde muito pequenas, elas procuram se situar em diversos espaços e tempos. Demonstram também curiosidade sobre o mundo físico e o mundo sociocultural. (BRASIL, 2017, p. 38). 
Figura 5 - Campo de experiências: espaços, tempos, quantidades, relações e transformações

\section{CAMPO DE EXPERIÊNCIAS "ESPAÇOS, TEMPOS, QUANTIDADES, RELAÇŌES E TRANSFORMAÇŐES"}

\begin{tabular}{|c|c|c|}
\hline $\begin{array}{l}\text { Crianças de zero a } \\
1 \text { ano } 06 \text { meses }\end{array}$ & $\begin{array}{l}\text { Criancas de } 1 \text { ano e } 7 \text { meses } \\
\text { a } 3 \text { anos o } 11 \text { moses }\end{array}$ & $\begin{array}{l}\text { Criancas de } 4 \text { anos a } \\
5 \text { anos e } 11 \text { meses }\end{array}$ \\
\hline $\begin{array}{l}\text { (Eloleto1) } \\
\text { Explorar e descobrir as } \\
\text { propriedades de objetos e } \\
\text { materiais (odor, cor, sabor, } \\
\text { temperatura). }\end{array}$ & $\begin{array}{l}\text { (EIO2ETO1) } \\
\text { Explorar e descrever } \\
\text { semelhanças e diferenças } \\
\text { entre as caracteristicas e } \\
\text { propriedades dos objetos } \\
\text { (sonoridade, textura, peso, } \\
\text { tamanho, posiço no } \\
\text { espaço). }\end{array}$ & $\begin{array}{l}\text { (ElO3ETO1) } \\
\text { Estabelecer relaçōes } \\
\text { de comparaç̄o entre } \\
\text { objetos, observando suas } \\
\text { propriedades. }\end{array}$ \\
\hline $\begin{array}{l}\text { (EIO1ETO2) } \\
\text { Explorar relaçóes de causa } \\
\text { e efeito (transbordar, tingir, } \\
\text { misturar, mover e remover } \\
\text { etc.) na interaçăo com o } \\
\text { mundo físico. }\end{array}$ & $\begin{array}{l}\text { (EIO2ETO2) } \\
\text { Observar, relatar e } \\
\text { descrever incidentes do } \\
\text { cotidiano e fenómenos } \\
\text { naturais (luz solar, vento, } \\
\text { chuva etc.). }\end{array}$ & $\begin{array}{l}\text { (EIO3ETO2) } \\
\text { Observar e descrever } \\
\text { mudanças em diferentes } \\
\text { materiais, resultantes } \\
\text { de açós sobre eles, em } \\
\text { experimentos envolvendo } \\
\text { fenômenos naturais e } \\
\text { artificiais. }\end{array}$ \\
\hline $\begin{array}{l}\text { (EIO1ETO3) } \\
\text { Explorar o ambiento } \\
\text { pela açăo e observaç̄o, } \\
\text { manipulando, } \\
\text { experimentando e fazendo } \\
\text { descobertas. }\end{array}$ & $\begin{array}{l}\text { (EIO2ETO3) } \\
\text { Compartilhar, com outras } \\
\text { criancas, situaçes de } \\
\text { cuidado de plantas o } \\
\text { animais nos espaços da } \\
\text { instituiça e fora dela. }\end{array}$ & $\begin{array}{l}\text { (EIO3ETO3) } \\
\text { Identificar e selecionar } \\
\text { fontes de informaḉes, } \\
\text { para rosponder a questōes } \\
\text { sobre a natureza, } \\
\text { seus fenómenos, sua } \\
\text { preservaça. }\end{array}$ \\
\hline $\begin{array}{l}\text { (EIO1ETO4) } \\
\text { Manipular, experimentar, } \\
\text { arrumar e explorar } \\
\text { o espaco por meio } \\
\text { de experiências de } \\
\text { doslocamentos de si e dos } \\
\text { objetos. }\end{array}$ & $\begin{array}{l}\text { (EIO2ETO4) } \\
\text { Identificar relaçles } \\
\text { espaciais (dentro e fora, } \\
\text { em cima, embaixo, acima, } \\
\text { abaixa, entre e do lado) e } \\
\text { temporais (antes, durante e } \\
\text { depois). }\end{array}$ & $\begin{array}{l}\text { (ElO3ETO4) } \\
\text { Registrar observaç̄es, } \\
\text { manipulacōes e medidas, } \\
\text { usando multiplas } \\
\text { linguagens (desenho, } \\
\text { registro por números ou } \\
\text { escrita espontânea), em } \\
\text { diferentes suportes. }\end{array}$ \\
\hline $\begin{array}{l}\text { (ElOIETO5) } \\
\text { Manipular materiais } \\
\text { diversos e variados para } \\
\text { comparar as diferencas e } \\
\text { semelhancas entre eles. }\end{array}$ & $\begin{array}{l}\text { (ElO2ETOS) } \\
\text { Classificar objetos, } \\
\text { considerando determinado } \\
\text { atributo (tamanho, poso, } \\
\text { cor, forma etc). }\end{array}$ & $\begin{array}{l}\text { (EIO3ETOS) } \\
\text { Classificar objotos e } \\
\text { figuras, de acordo com } \\
\text { suas semelhancas e } \\
\text { diferencas. }\end{array}$ \\
\hline
\end{tabular}




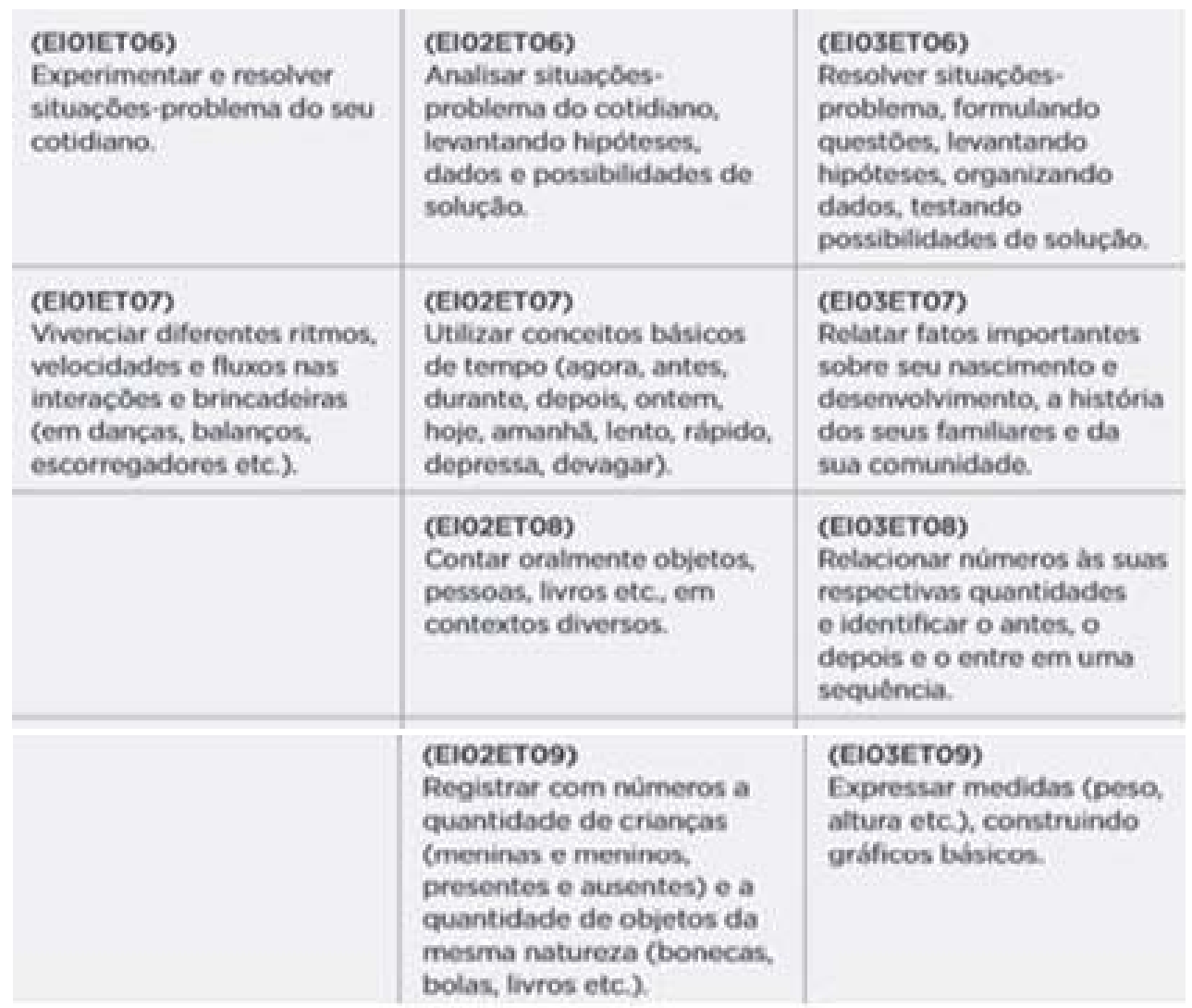

Fonte: Base Nacional Curricular da Educação Infantil (BRASIL, 2017).

De modo geral, os objetivos apresentados no quadro anterior se relacionam à descoberta de atributos dos objetos, à comparação de objetos, à relação causa e efeito, à estrutura de número e, também, a um objetivo relacionado ao relato de fatos importantes como nascimento, história de familiares. Predominam no desenvolvimento de objetivos aqueles relacionados ao pensamento lógico com ênfase na área de matemática. Consideramos, portanto, que as questões relacionadas ao contexto social poderiam ter sido abordadas, estruturalmente, no campo de experiências: O eu, o outro e o nós. Como já afirmamos, trata-se de uma questão didática para organização e enriquecimento das abordagens curriculares para a Educação Infantil. Nas práticas pedagógicas, as propostas integram diferentes campos de experiências. No que se refere aos objetivos pensados para as crianças de zero a um ano e seis meses, o foco é a exploração, a manipulação de 
objetos e a vivência. Consideramos que os objetivos possibilitam o conhecimento de mundo pela criança. Já para crianças de 1 ano e sete meses a 3 anos e 11 meses, os objetivos são descritos por verbos como: descrever, explorar observar, compartilhar, identificar, comparar, analisar, utilizar conceitos, contar, evidenciando um salto evolutivo em relação aos objetivos da primeira faixa etária. O objetivo é Compartilhar com outras crianças, situações de cuidado de plantas e animais nos espaços da instituição e fora dela. Levanta dúvidas tais como: As crianças vão relatar como cuidam de plantas e animais? Irão cuidar de plantas e animais na escola? Esse tema se refere apenas a crianças dessa faixa etária? Para crianças de 4 anos a 5 anos e 11 meses, a ênfase é nos objetivos relacionados à capacidade da criança de estabelecer relações como descrever mudanças, selecionar fontes de informação, expressar medidas, construir gráficos. Entendemos que a expressão de medidas se refere à exposição de dados nos gráficos, mas destacamos que a capacidade de medir envolve a capacidade de relações lógicas. Observamos também nesse campo de experiências uma tentativa de graduação de complexidade em alguns objetivos, como no caso do sexto objetivo para as três faixas etárias. Na primeira faixa etária é: Experimentar e resolver situações-problema do seu cotidiano. Já na segunda faixa etária, trata-se de: Analisar situações - problema do cotidiano, levantando hipóteses, dados e possibilidades de solução. E, finalmente, para a terceira faixa etária é: Resolver situações-problema, formulando questões, levantando hipóteses, organizando dados, testando possibilidades de solução. A questão que colocamos é: Em que base teórica, foi baseada a graduação dos objetivos?

Entendemos que os objetivos elencados para esse campo de experiências poderiam ser enriquecidos evidenciando outros objetivos relacionados à compreensão do mundo físico e do mundo social, abordado de modo superficial. Esses objetivos deveriam ser aprofundados no campo de experiências: $\mathrm{O}$ eu, o outro e o nós.

\section{CONSIDERAÇÕES FINAIS: ALGUNS APONTAMENTOS SOBRE A BNCC}

A análise da BNCC da Educação Infantil quanto à sua organização e, especialmente, às concepções de criança e de desenvolvimento, do seu arranjo curricular permitem fazer algumas considerações. 
A concepção de criança como sujeito histórico, social e cultural, defendida nos princípios do documento, não apresenta uma efetiva coerência na abordagem dos campos de experiências. Há uma certa linearidade na definição dos objetivos relacionados ao desenvolvimento /aprendizagem nos diferentes campos de experiências, o que pode relativizar a dinamicidade o movimento presente no processo de construção de conhecimentos de uma criança como sujeito histórico social.

Não há clareza nos quadros dos campos de experiências sobre o significado de objetivos de aprendizagem e de desenvolvimento infantil e sobre a relação desenvolvimento e aprendizagem.

Para organizar objetivos para três faixas etárias, é necessário o cuidado para não fragmentar o processo educativo com a visão de que com crianças se desenvolver linearmente em três etapas etárias isoladas. Essa fragmentação poderia empobrecer e /ou padronizar o desenvolvimento da criança.

As diversas formas de expressão e linguagens deveriam ser objeto do campo de experiências Traços, sons, cores e formas, e não deveriam ter sido abordadas superficialmente no campo Corpo, gestos e movimentos.

Os temas sociais, as questões socioculturais deveriam ser abordadas e valorizadas no campo de experiências $O$ eu, o outro e o nós, e não apenas pincelados no campo de experiências Espaços, tempos, quantidades, relações e transformações. Os aspectos sociais e culturais não foram valorizados no arranjo proposto na BNCC.

Conceitos relacionados à língua, oralidade e escrita precisam ser compreendidos e explicitados no campo de experiências Oralidade e Escrita.

Cabe salientar que a divisão dos campos de experiências se constitui numa organização didática, mas que, nas práticas educativas, a integração dos campos de experiências se constitui como caminho metodológico. Assim, um trabalho pedagógico na Educação Infantil que fragmenta o chamado arranjo curricular proposto em disciplinas ou em áreas de conhecimento isoladamente demonstra a fragilidade dessa base curricular.

Os quadros de cada campo de experiências deveriam passar por uma revisão do que se constitui como objetivo e atividade e, do que se apresenta, ao mesmo tempo, como objetivo e atividade.

É de fundamental importância a elucidação das bases teóricas que fundamentam o texto da BNCC da Educação Infantil. Essa elucidação deveria ser explicitada no corpo do texto por meio de fundamentos teórico-metodológicos 
que precisam ser aprofundados e discutidos pelos professores.

No que se refere a construção do currículo em cada unidade escolar, concordamos com Kramer (1997, p. 16) quando afirma que: "Um currículo ou proposta pedagógica reúne tanto as bases teóricas, quanto as diretrizes práticas nela fundamentadas, bem como aspectos de natureza técnica que viabilizam a sua concretização". Nesse sentido, cabe às secretarias municipais de educação, às unidades escolares se debruçarem no estudo da BNCC, pensarem nas diretrizes práticas, nos aspectos técnicos, nas condições concretas de trabalho e no processo de ampliação de formação dos educadores, para uma análise crítica. Um currículo não pode ser reduzido ao campo das ideias, a busca pela construção de uma proposta pedagógica significativa consiste num processo a ser assumido coletivamente, o que exige a reflexão e a tomada de decisões coletivas acerca de diferentes aspectos que constituem ou interferem no processo educativo das crianças.

Para finalizar, destacamos o caráter político presente nas decisões educativas ao nos referirmos a currículo ou a proposta pedagógica. Como Kramer (2003, p. 169), "Entendemos que a Proposta Pedagógica contém subjacente uma concepção de homem, de sociedade a qual definirá o tipo de conhecimento que deverá ser ensinado para que aquele indivíduo venha a tornar se desejável e útil aquela sociedade". Que o currículo contribua para a formação de um sujeito autônomo e crítico, capaz de participar efetivamente na sociedade.

\section{REFERÊNCIAS}

BARBOSA, M. C. S. et al. Práticas cotidianas na educação infantil - bases para a reflexão sobre as orientações curriculares para a educação infantil. Brasília: MEC/SEB/UFRGS, 2009.

BRASIL. Ministério da Educação. Base Nacional Comum Curricular. Brasília: MEC, 2017. Disponível em: <http://basenacionalcomum.mec.gov.br/>. Acesso em: 8 set. 2017.

KISHIMOTO, T. M. Currículo de educação infantil: creches e pré-escolas. Significado do termo currículo, currículo de educação infantil: critérios de qualidade e instrumentos de implementação. Texto encomendado pela coordenação geral de Educação Infantil do MEC. 1994. (mimeo).

KRAMER, S. Propostas pedagógicas ou curriculares: subsídios para uma leitura crítica. In: MOREIRA, A. F. (Org.). Currículo: políticas e práticas em educação. Campinas, SP: Papirus: 2003. p. 165-83.

KRAMER, S. Propostas pedagógicas ou curriculares: subsídios para uma leitura crítica. 
Educação \& Sociedade, Campinas, SP, v. 18, n. 60, p. 15-35, dez. 1997 . Disponível em: <http://www.scielo.br/scielo.php?pid=S0101-73301997000300002\&script=sci_ abstract\&tlng=pt>. Acesso em: 15 maio 2002.

LOPES, D. M. de C.; SOBRAL, E. L. S. Debates em educação - educação infantil e currículo: políticas e práticas. Debates em Educação, Maceió, AL, v. 6, n. 11, p. 74-103, jan./jun. 2014.

OLIVEIRA, Z. de M. R. O currículo na educação infantil: o que propõe as novas diretrizes nacionais? In: SEMINÁRIO NACIONAL: CURRÍCULO EM MOVIMENTO - PERSPECTIVAS ATUAIS, 1. Anais... Belo Horizonte, nov. 2010.

PALANGANA, I. C. A função da linguagem na formação da consciência: reflexões. Cadernos do Cedes, Campinas, SP, n. 35, 1995.

SIRGADO, A. P. O conceito de mediação semiótica em Vygotsky e seu papel na explicação do psiquismo humano. Cadernos Cedes, Campinas, SP, n. 24, p. 32-43, 2000.

VYGOTSKY, L. S. A formação social da mente. 5. ed. São Paulo: Martins Fontes, 1998.

\section{Sobre as autoras:}

Ana Maria Esteves Bortolanza: Estágio de Pós-Doutoramento na Universidade de Évora. Doutora em Educação Brasileira pela Universidade Estadual "Júlio de Mesquita Filho" (UNESP). Mestrado Profissional em Educação: Formação Docente para a Educação Básica. Docente da Universidade de Uberaba. E-mail: amebortolanza@uol.com.br

Renata Teixeira Junqueira Freire: Doutora em Educação pela Universidade Pontifícia Universidade Católica de São Paulo (PUC/SP). Docente da Universidade de Uberaba - Programa de Pós-Graduação em Educação. E-mail: renatatjunqueirafreire@gmail.com

\section{Recebido em fevereiro de 2018 \\ Aprovado em maio de 2018}

